\title{
Synthesis of Polymers in Aqueous Solutions. Selective Addition Reaction of Poly(2-isopropenyl-2-oxazoline) with Thiols and Carboxylic Acids in Aqueous Solutions
}

\author{
Tadatomi Nishikubo, ${ }^{* \dagger}$ Atsushi Kameyama, and Hiroyuki ToKaI \\ Department of Applied Chemistry, Faculty of Engineering, Kanagawa University, \\ Rokkakubashi, Kanagawa-ku, Yokohama 221, Japan
}

(Received June 14, 1995)

\begin{abstract}
Convenient addition reactions of 2-methyl-2-oxazoline (1a) and poly(2-isopropenyl-2-oxazoline) (5) with benzenethiol (2a) in the aqueous solution were examined. The reaction of $\mathbf{1 a}$ with $\mathbf{2 a}$, which is a model reaction for polymer synthesis, in mixed solvents of $N$-methyl-2-pyrrolidone (NMP) and water at $60^{\circ} \mathrm{C}$ for $1 \mathrm{~h}$ gave only an adduct $N$-(2phenylthioethyl)acetamide (3a) in $72-77 \%$ yields. However, adduct 3a and a hydrolysis product $N$-(2-hydroxyethyl)acetamide (4) were obtained in 67 and $23 \%$ yields, respectively, when the reaction of 1a with equivalent 2 a was carried out in water alone at $60^{\circ} \mathrm{C}$ for $3 \mathrm{~h}$. The addition reactions of pendant oxazoline groups in polymer 5 with thiols such as $2 \mathrm{a}$, $S$-thioacetic acid (2c), $S$-thiobenzoic acid (2d) proceeded quantitatively to give the corresponding polymers $(\mathbf{6 a}, \mathbf{6 c}$, and $\mathbf{6 d})$ without hydrolysis of the pendant oxazoline groups in the mixed solvents of NMP with water. It was also found that the addition reactions of the pendant oxazoline groups in polymer $\mathbf{5}$ with $\mathbf{2 a}$ proceeded with high conversion and selectively without hydrolysis of the oxazoline groups even when water was used as the reaction medium.

KEY WORDS Reaction Medium / Aqueous Solution / Addition Reaction / 2-Methyl-2-oxazoline /

Poly(2-isopropenyl-2-oxazoline) / Bezenethiol /
\end{abstract}

Careful removal of water is required in many cases in synthetic organic chemistry and synthetic polymer chemistry, because most organic reactions, especially ionic reactions, are strongly hindered by the presence of water. However, it would seem that water and aqueous solutions could have great possibilities as reaction media from the viewpoints of incombustibility, safety, and economics in chemical laboratory and chemical industry. In fact, suspension polymerization and emulsion polymerization of vinyl acetate, vinyl chloride, styrene, butadiene, and other monomers with radical initiators using water as a reaction medium have long been done for the preparation of polymers in the laboratory and industry.

In recent years, phase transfer reactions between the organic phase and the aqueous phase as well as the solid phase have been employed conveniently for various organic reactions ${ }^{1}$ such as substitution, elimination, and oxidation reactions. These heterogeneous reaction systems can also be used for polymer synthesis ${ }^{2}$ and chemical modification of polymers ${ }^{3}$ under mild reaction conditions. More recently, Breslow et al. ${ }^{4}$ and Grieco et $a l .{ }^{5}$ found independently that Diels-Alder reactions of dienes with dienophiles were strongly enhanced using water as a reaction medium due to the hydrophobic interaction between two reactants or by micellar catalysis resulting in mutual binding of the reactants. Kobayashi et al. ${ }^{6}$ reported that Aldol reactions of silyl enol ethers with aldehydes proceed very smoothly in aqueous solution catalyzed by lanthanide trifrates. However, there is no other reports on the synthesis of polymers in aqueous solution.

The authors reported ${ }^{7,8}$ recently that the addition reactions of pendant cyclic iminoether groups such as oxazoline and oxazine groups in the polymers with

${ }^{\dagger}$ To whom all correspondence should be addressed. thiols and carboxylic acids proceed very smoothly in $\mathrm{N}$-methyl-2-pyrrolidone (NMP), and reactions with dithiols and dicarboxylic acids also proceed in the film state to give the corresponding gel products. Poly(2-vinyl2-oxazoline) is very soluble in water ${ }^{7}$ as is 2-methyl-2oxazoline (1a).

Given this background, it seems reasonable to us that the aqueous solutions might be utilized widely for the polymer synthesis. This article reports on the addition reactions of low molecular weight oxazoline compounds and pendant oxazoline group in the polymer with certain thiols and with carboxylic acids in aqueous solution and in water.

\section{RESULTS AND DISCUSSION}

Addition reactions of $\mathbf{1 a}$ and 2-phenyl-2-oxazoline (1b) with benzenethiol (2a) proceeded $^{7,9}$ to give the corresponding adducts $N$-(2-phenylthioethyl)acetamide (3a) and $N$-(2-phenylthioethyl)-benzamide (3b) in high yields, respectively. However, there is no report on the relative reactivity of oxazolines with thiols. Therefore, the reactivity of $\mathbf{1 a}$ and $\mathbf{1 b}$ with $\mathbf{2} \mathbf{a}$ and phenylmethanethiol (2b) was examined in NMP at $90^{\circ} \mathrm{C}$ under nitrogen. As shown in Figure 1, the reaction of $1 \mathbf{a}$ with 2a proceeded quantitatively in only $15 \mathrm{~min}$ to give $\mathbf{3 a}$, and the reaction of $\mathbf{1 b}$ with $\mathbf{2} \mathbf{a}$ gave $\mathbf{3 b}$ in very high yield at $5 \mathrm{~h}$. On the other hand, the rate of addition reaction of $\mathbf{1 a}$ with $\mathbf{2 b}$ was very slow, and the reaction of $\mathbf{1 b}$ with $\mathbf{2 b}$ did not occur under the same conditions. This suggests that 1a with electron donative methyl group has higher reactivity than $\mathbf{1 b}$ with bulky and electron withdrawing phenyl groups to thiols, and $\mathbf{2 a}$ with strong electrophilicity has higher reactivity than $\mathbf{2 b}$ to oxazoline compounds.

Based on the above reactivity of oxazolines with thiols, the addition reaction of $\mathbf{1 a}$ with $\mathbf{2 a}$ was performed in 


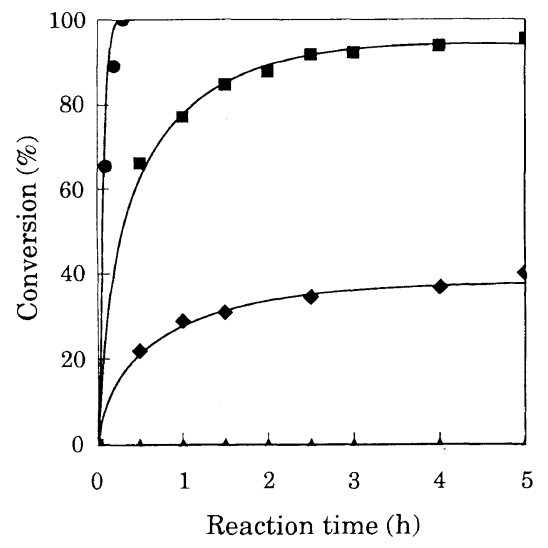

Figure 1. Rates of addition reactions of oxazolines with thiols: The reaction was carried out with oxazoline $(10 \mathrm{mmol})$ and thiol $(10 \mathrm{mmol})$ in NMP $(10 \mathrm{ml})$ at $90^{\circ} \mathrm{C}$ under nitrogen. (O) 1a with $\mathbf{2 a}$; (ם) $\mathbf{1 b}$ with $\mathbf{2 a}$; (•) $\mathbf{1 a}$ with $\mathbf{2 b}$; (A) $\mathbf{1 b}$ with $\mathbf{2 b}$.

Table I. Conditions and results of addition reactions of $1 \mathbf{a}$ with $\mathbf{2 a}$ in aqueous solution ${ }^{\mathrm{a}}$

\begin{tabular}{|c|c|c|c|}
\hline \multirow{2}{*}{$\begin{array}{l}\text { Run } \\
\text { No. }\end{array}$} & NMP/water & Time & Yield $^{b}$ \\
\hline & ratio & $\mathrm{h}$ & $\%$ \\
\hline 1 & $10 / 0$ & 1 & 76 \\
\hline 2 & $8 / 2$ & 1 & 77 \\
\hline 3 & $7 / 3$ & 1 & 76 \\
\hline 4 & $6 / 4$ & 1 & 77 \\
\hline 5 & $5 / 5$ & 1 & 72 \\
\hline 6 & $2 / 8$ & 1 & 73 \\
\hline 7 & $0 / 10$ & 1 & 52 \\
\hline 8 & $0 / 10$ & 2 & 54 \\
\hline 9 & $0 / 10$ & 3 & $55(63)^{\mathrm{c}}$ \\
\hline
\end{tabular}

a The reaction was carried out with $\mathbf{1 a}(10 \mathrm{mmol})$ and $\mathbf{2 a}(10 \mathrm{mmol})$ in aqueous solution $(10 \mathrm{ml})$ at $60^{\circ} \mathrm{C}$ under $\mathrm{N}_{2} \cdot{ }^{\mathrm{b}}$ Isolated yield of adduct 3a. ${ }^{\mathbf{c}}$ Total yield of precipitated $\mathbf{3 a}$ and extracted $\mathbf{3 a}$ from the reaction solvent.

mixed solvents of NMP with water at $60^{\circ} \mathrm{C}$ under nitrogen as a model reaction for polymer synthesis. As summarized in Table I, 3a was obtained in $76 \%$ yield from the reaction in NMP at $1 \mathrm{~h}$. 3a was also prepared with $73-77 \%$ yields from the reaction in mixed solvents of NMP with water, although the yield decreased gradually with increasing water. This suggests that the addition reaction of $\mathbf{1 a}$ with $\mathbf{2 a}$ proceeds very smoothly in mixed solvents of NMP with water (run no. 2, 3, and 4) as it does in NMP.

The yields of recovered 3a, which precipitated during the reaction, were only 52,54 , and $55 \%$ in water at 1 , 2 , and $3 \mathrm{~h}$, respectively. Accordingly, the addition reaction of 1a with $2 \mathrm{a}$ was carried out in water at $60^{\circ} \mathrm{C}$ for $3 \mathrm{~h}$. The isolation of reaction products was performed by silica gel column chromatography using methanol as the eluent, and 3a and $N$-(2-hydroxyethyl)acetamide (4) were isolated in 63 and $27 \%$ yields, respectively. These results suggest that some hydrolysis of 1a occurrs ${ }^{10-13}$ as a side reaction on the addition reaction of 1a with 2a in water. It seems that the hydrolysis of $1 \mathrm{a}$ also occurrs slightly as a side reaction in the mixed solvents containing many amounts of water, especially in runs 5 and 6 .

Therefore, to confirm the reactivity of oxazoline with water, the reaction of $\mathbf{1 a}$ with water was examined. As shown in Figure 2, the hydrolysis of 1 a proceeded

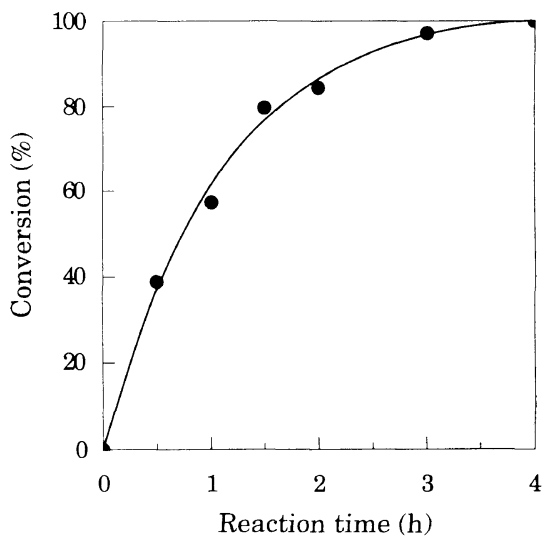

Figure 2. Rate of hydrolysis of $\mathbf{1 a}$ by water. The reaction was carried out with 1 a $(10 \mathrm{mmol})$ in excess water $(277 \mathrm{ml})$ at $60^{\circ} \mathrm{C}$.

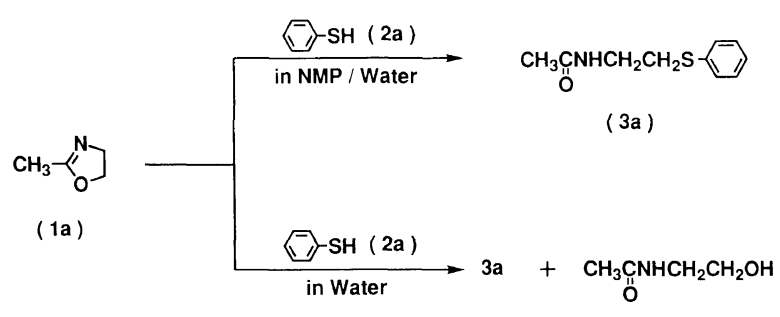

(4)

Scheme 1.

smoothly at $60^{\circ} \mathrm{C}$ to give adduct 4 in quantitative yield. This means that although the addition reaction of $\mathbf{1 a}$ with 2a proceeds with excellent selectivity even in the mixed solvent of NMP with water, disappointingly the hydrolysis of 1a also occurrs as a side reaction when the reaction is performed using water as the reaction medium.

Based on the above reactions of low molecular weight oxazolines with thiols, the addition reaction of poly(2-isopropenyl-2-oxazoline) (5) with 2a was examined in mixed solvents of dimethyl sulfoxide (DMSO), dimethylformamide (DMF), diglyme and NMP with water, and only in water at $60^{\circ} \mathrm{C}$ under nitrogen. The addition reactions of pendant oxazoline groups in polymer $\mathbf{5}$ with $\mathbf{2 a}$ proceeded with high conversions (79-84\%) to give the corresponding polymers (6a) when performed in the above mixed solvents (vol. ratio: $7 / 3$ ) for $1 \mathrm{~h}$ (runs $10-12$ ), and reactions in a mixture of NMP with water showed the highest degrees of addition (DA) (95\%) (run 13). In Figure $3,{ }^{1} \mathrm{H}$ NMR spectra of the model compound 3a, reaction product with water $\mathbf{4}$, starting polymer $\mathbf{5}$, and obtained polymer $\mathbf{6 a}$ with $100 \%$ DA are summarized to identify the structure of 6a. However, there is no appearance of $\mathrm{OH}$ or other proton signals due to the pendant 2-hydroxyethylamide group in the spectrum of $\mathbf{6 a}$. This means that the addition reactions of the pendant oxazoline groups in polymer $\mathbf{5}$ with 2a proceed selectively without hydrolysis of the pendant oxazoline groups.

Furthermore, the addition reactions of the pendant oxazoline groups in polymer $\mathbf{5}$ with 2 a proceeded with $100 \%$ conversion for $5 \mathrm{~h}$ (run 14). The degree of addition of 2a to the pendant oxazoline groups in polymer 5 decreased slightly with increasing water in the mixed solvent (vol. ratio: 3/7) (run 15). 


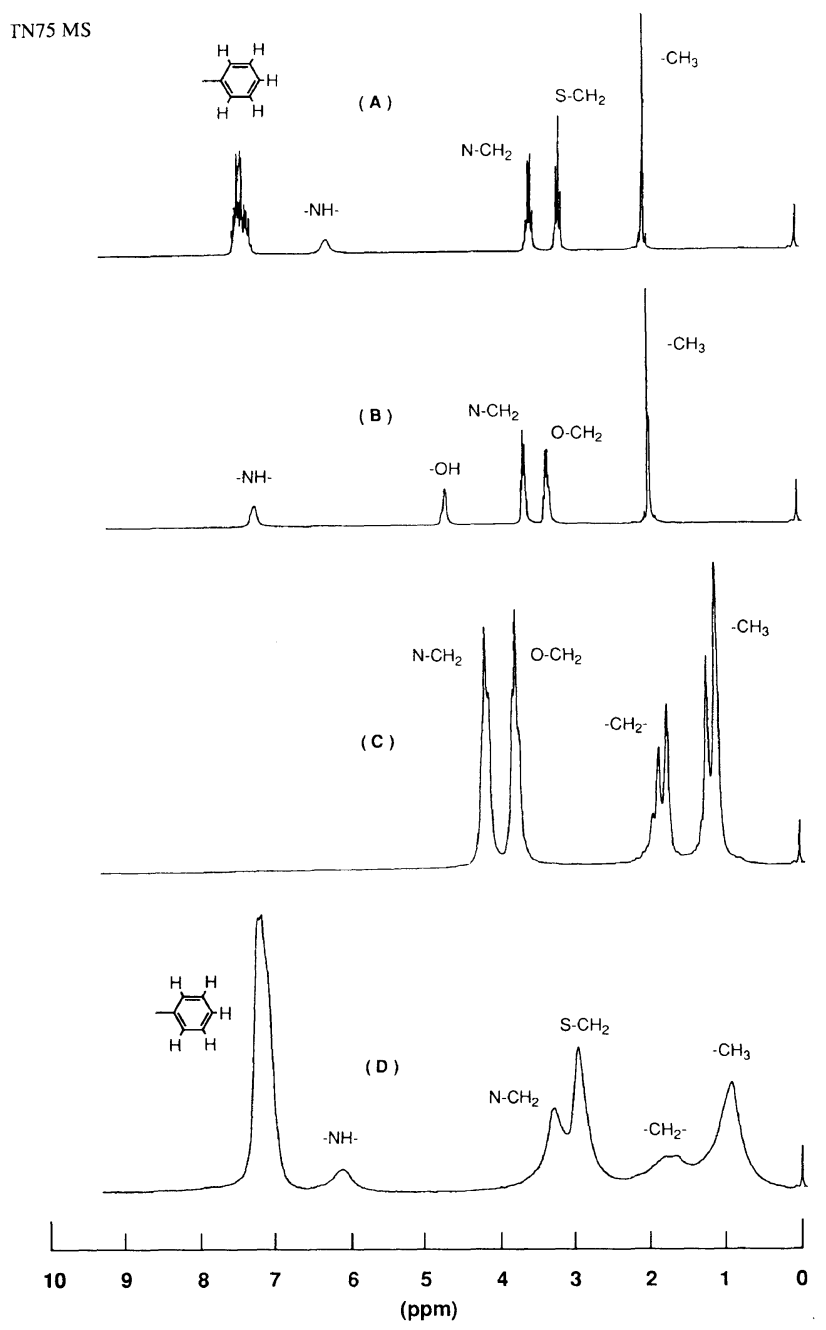

Figure 3. ${ }^{1} \mathrm{H}$ NMR spectra $(200 \mathrm{MHz})$ of polymer 6a and related compounds, as measured $\mathrm{CDCl}_{3}$. (A) 3a measured at $27^{\circ} \mathrm{C}$, (B) 4 measured at $27^{\circ} \mathrm{C}$; (C) polymer 5 measured at $50^{\circ} \mathrm{C}$; (D) polymer $6 \mathrm{a}$ with $100 \%$ DA measured at $50^{\circ} \mathrm{C}$.

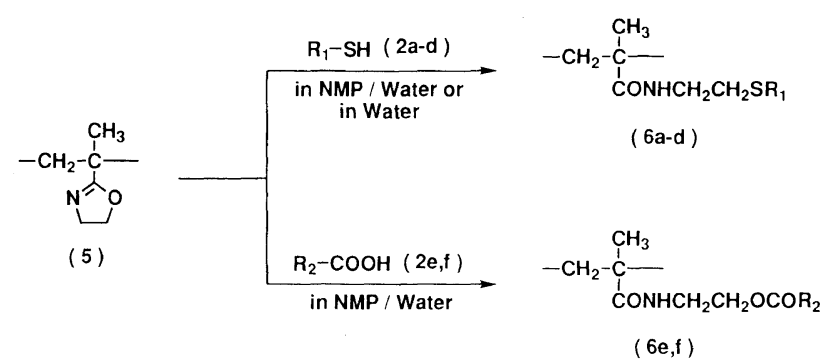

$\mathrm{R}_{1}=\bigotimes(2 \mathrm{a}, 6 \mathrm{a}), \quad \circlearrowleft \mathrm{CH}_{2}(2 \mathrm{~b}, 6 \mathrm{~b}), \mathrm{CH}_{3} \mathrm{CO}(2 \mathrm{c}, 6 \mathrm{c}),(1) \mathrm{CO}(2 \mathrm{~d}, 6 \mathrm{~d})$

$\left.\mathrm{R}_{2}=\mathrm{CH}_{3}(2 \mathrm{e}, 6 \mathrm{e}), 0(2 \mathrm{O}), 6 \mathrm{f}\right)$

Scheme 2.

The addition reaction of polymer $\mathbf{5}$ with $\mathbf{2 a}$ also proceeded very smoothly with 74 and $81 \%$ conversions, when the reaction was carried out in water at 1 and $5 \mathrm{~h}$, respectively (runs 16,17 ). Although the reaction of $1 \mathbf{a}$ with $\mathbf{2 a}$ in water produced $\mathbf{4}$ as the hydrolysis by-product under the same conditions, interestingly enough, the IR and ${ }^{1} \mathrm{H}$ NMR spectra of the resulting polymers did not show evidence of hydrolysis of the pendant oxazoline groups in the polymer. This means that the addition reactions of the pendant oxazoline groups in polymer $\mathbf{5}$ with $\mathbf{2 a}$ proceed with very high
Table II. Conditions and results of addition reactions of polymer $\mathbf{5}$ with $\mathbf{2 a}$ in various aqueous solution ${ }^{\mathbf{a}}$

\begin{tabular}{|c|c|c|c|c|c|}
\hline \multirow{2}{*}{$\begin{array}{l}\text { Run } \\
\text { No. }\end{array}$} & \multirow{2}{*}{$\begin{array}{c}\text { Organic } \\
\text { solvent }\end{array}$} & Org. solv./water & Time & Yield $^{\mathrm{b}}$ & $\mathrm{DA}^{\mathrm{c}}$ \\
\hline & & ratio & $\mathrm{h}$ & $\%$ & $\%$ \\
\hline 10 & DMSO & $7 / 3$ & 1 & 95 & 84 \\
\hline 11 & DMF & $7 / 3$ & 1 & 92 & 82 \\
\hline 12 & Diglyme & $7 / 3$ & 1 & 94 & 79 \\
\hline 13 & NMP & $7 / 3$ & 1 & 90 & 95 \\
\hline 14 & NMP & $7 / 3$ & 5 & 87 & 100 \\
\hline 15 & NMP & $3 / 7$ & 1 & 84 & 91 \\
\hline 16 & - & $0 / 10$ & 1 & 93 & 4 \\
\hline 17 & - & $0 / 10$ & 5 & 86 & 81 \\
\hline
\end{tabular}

a The reaction was carried out with polymer $5(4 \mathrm{mmol})$ and 2 a $(4 \mathrm{mmol})$ in aqueous solution $(4 \mathrm{ml})$ at $60^{\circ} \mathrm{C}$ under $\mathrm{N}_{2} \cdot{ }^{\mathrm{b}}$ Recovered polymer yield was corrected based on DA. ${ }^{\mathrm{c}}$ Degree of the addition of 2a to the pendant oxazoline group, as calculated from the intensity ratio of ${ }^{1} \mathrm{H}$ NMR spectrum of the resulting polymer $\mathbf{6 a}$.

Table III. Conditions and results of addition reactions of polymer $\mathbf{5}$ with various thiols and carboxylic acids in aqueous solution ${ }^{\mathrm{a}}$

\begin{tabular}{|c|c|c|c|c|}
\hline \multirow{2}{*}{$\begin{array}{l}\text { Run } \\
\text { No. }\end{array}$} & \multirow{2}{*}{$\begin{array}{c}\text { Thiol or } \\
\text { carboxylic acid }\end{array}$} & Time & \multirow{2}{*}{$\frac{\text { Yield }^{\mathrm{b}}}{\%}$} & \multirow{2}{*}{$\frac{\mathrm{DA}}{\%}$} \\
\hline & & $\mathrm{h}$ & & \\
\hline 13 & $2 a$ & 1 & 90 & 95 \\
\hline 18 & $2 b$ & 1 & 91 & 2 \\
\hline 19 & $2 c$ & 1 & 82 & 100 \\
\hline 20 & $2 d$ & 1 & 62 & 100 \\
\hline 21 & $2 e$ & 24 & 91 & 42 \\
\hline 22 & $2 f$ & 24 & 91 & 64 \\
\hline
\end{tabular}

a The reaction was carried out with polymer $5(4 \mathrm{mmol})$ and thiol (or carboxylic acid) $(4 \mathrm{mmol})$ in a mixed solvent of NMP $(2.8 \mathrm{ml})$ and water $(1.2 \mathrm{ml})$ (ratio: $7 / 3$ ) at $60^{\circ} \mathrm{C}$ under $\mathrm{N}_{2} \cdot{ }^{\text {b }}$ Recovered polymer yield was corrected based on DA. ${ }^{\mathrm{c}}$ Degree of addition of thiol or carboxylic acid to the pendant oxazoline group, as calculated from the intensity ratio of ${ }^{1} \mathrm{H}$ NMR spectrum of the resulting polymers $\mathbf{6 a - 6 f}$.

chemical selectivity to give the corresponding polymer (6a) even in aqueous solution due to hydophobic interaction between the polymer chain and reagent, which increased with DA of the polymer, or due to favorable steric hindrance of the polymer chain.

Some addition reactions of oxazoline polymer 5 with other thiols and carboxylic acids were examined in a mixed solvent (vol. ratio: 7/3) of NMP with water at $60^{\circ} \mathrm{C}$ under nitrogen. As summarized in Table III, although the degree of addition of $\mathbf{2} \mathbf{b}$ to the pendant oxazoline groups in polymer 5 was only $2 \%$ (run 18), the hydrolysis of the pendant oxazoline groups in polymer 5 did not occur, which was confirmed by the IR and ${ }^{1} \mathrm{H}$ NMR spectra of the resulting polymer. The addition reaction with $\mathrm{S}$-thioacetic acid $(\mathbf{2 c})$ and with $S$-thiobenzoic acid (2d) proceeded very smoothly with $100 \%$ conversions to give the corresponding polymers (6c and 6d), respectively, when the reaction was carried out at $1 \mathrm{~h}$ (runs 19,20). This means that $S$-thiocarboxylic acids such as $\mathbf{2 c}$ and $\mathbf{2 d}$ with strong electrophilicity as well as $\mathbf{2 a}$ have high reactivity with oxazoline groups.

The addition reactions of polymer 5 with acetic acid (2e) and benzoic acid (2f) proceeded selectively with 65 and $42 \%$ conversions to give the corresponding polymers (6e and 6f) without hydrolysis of the pendant oxazoline groups, as confirmed by the IR and ${ }^{1} \mathrm{H}$ NMR spectra 
of the resulting polymers, when the reaction was carried out at $24 \mathrm{~h}$ under the same conditions (runs 21, 22). This suggests that selective chemical modification of the pendant oxazoline groups in the polymer by reaction with carboxylic acids was also possible in aqueous solution.

\section{EXPERIMENTAL}

\section{Materials}

All solvents were purified by distillation before use. Commercial reagent grade $\mathbf{1 a}, \mathbf{1 b}, \mathbf{2 a}, \mathbf{2 b}, \mathbf{2 c}, \mathbf{2 d}, \mathbf{2 e}$, and $\mathbf{2 f}$ were used without further purification. Oxazoline polymer $\mathbf{5}$ was provided by Nihon Shokubai Kagaku Co., Ltd. and purified by reprecipitation from chloroform into diethyl ether.

\section{Apparatus}

IR spectrum (film) of $5 ; 1657 \mathrm{~cm}^{-1}(\mathrm{C}=\mathrm{N}),{ }^{1} \mathrm{H}$ NMR spectrum of this polymer (in $\mathrm{CDCl}_{3}$ ); $\delta 0.64-1.36$ (br, $3 \mathrm{H}, \mathrm{CH}_{3}$ ), $1.60-2.28$ (br, $2 \mathrm{H}, \mathrm{CH}_{2}$ in the main chain), $3.56-3.96\left(\mathrm{br}, 2 \mathrm{H}, \mathrm{CH}_{2}-\mathrm{N}\right)$, and $3.96-4.72 \mathrm{ppm}(\mathrm{br}$, $\left.2 \mathrm{H}, \mathrm{CH}_{2}-\mathrm{O}\right)$. The number average molecular weight $\left(M_{n}\right)$ of polymer $5 ; 2.35 \times 10^{4}\left(M_{w} / M_{n}=1.80\right)$. Infrared (IR) spectra were measured on a JASCO Model IR-700 spectrometer. The ${ }^{1} \mathrm{H}$ NMR spectra were recorded on JEOL Model JMS FX-200 $(200 \mathrm{MHz})$ instruments in $\mathrm{CDCl}_{3}$ with $\mathrm{Me}_{4} \mathrm{Si}$ [tetramethylsilane (TMS)] as the internal standard. Molecular weights of the polymers were estimated by gel permeation chromatography (GPC) with the use of a Toso Model HLC-8020 GPC equipped with a refractive index detector using TSK gel (GMHXL) columns (eluent: DMF, calibrated with narrow molecular weight polystyrene standards). GLC analysis was carried out on a Shimadzu Model GC9AM gas chromatograph with a $3.2 \mathrm{~mm} \times 2.2 \mathrm{~m}$ column packed with $3 \%$ Silicon OV-101 on Shimalite W (AW-DMCS).

\section{Measurement of Conversion of Oxazoline Compound and Pendant Oxazoline Group in the Polymer}

The degree of addition of low molecular weight oxazoline compounds $\mathbf{1 a}$ and $\mathbf{1 b}$ with thiols $(\mathbf{2 a}, \mathbf{2} \mathbf{b})$ was periodically analyzed by GLC. The degree of addition of the pendant oxazoline groups in polymer 5 with thiols and carboxylic acids was determined by ${ }^{1} \mathrm{H}$ NMR spectrum of the resulting polymers.

\section{Typical Procedure for the Model Reaction. Addition Reaction of 2-Methyl-2-oxazoline (1a) with Benze- nethiol (2a) in Aqueous Solution}

$1 \mathrm{a}(0.851 \mathrm{~g} ; 10 \mathrm{mmol})$ was dissolved in a mixed solvent of NMP (12 ml) and water $(8 \mathrm{ml})$, and then $2 \mathbf{a}(1.102 \mathrm{~g}$; $10 \mathrm{mmol})$ was added to the solution. The mixture was stirred at $60^{\circ} \mathrm{C}$ for $1 \mathrm{~h}$ under nitrogen, and poured into a $5 \%$ solution of sodium carbonate and water $(100 \mathrm{ml})$. The precipitated white solid was filtered, recrystallized twice with water, and dried in vacuo. Yield of adduct 3a was $1.507 \mathrm{~g}(76 \%) . \mathrm{mp} 89-90^{\circ} \mathrm{C}$. $\left(\mathrm{Lit}^{14} ; 88-89^{\circ} \mathrm{C}\right)$. IR $(\mathrm{KBr})$; $3284(\mathrm{NH}), 3080$ and $2920(\mathrm{CH}), 1650(\mathrm{C}=\mathrm{O})$, and $1553(\mathrm{NH}) \mathrm{cm}^{-1} .{ }^{1} \mathrm{H}$ NMR $\left(\mathrm{CDCl}_{3}, \mathrm{TMS}\right) ; \delta 1.94$ $\left(\mathrm{s}, 3 \mathrm{H}, \mathrm{CO}-\mathrm{CH}_{3}\right), 3.06\left(\mathrm{t}, J=6.2 \mathrm{~Hz}, 2 \mathrm{H}, \mathrm{S}-\mathrm{CH}_{2}\right), 3.45$ $\left(\mathrm{dt}, J_{\mathrm{ab}}=J_{\mathrm{ac}}=6.2 \mathrm{~Hz}, 2 \mathrm{H}, \mathrm{N}-\mathrm{CH}_{2}\right), 6.00(\mathrm{br} \mathrm{s}, 1 \mathrm{H}$,
$\mathrm{NH})$, and $7.08-7.48 \mathrm{ppm}(\mathrm{m}, 5 \mathrm{H}$, aromatic protons).

\section{Addition Reaction of 2-Methyl-2-oxazoline (1a) with} Water

The reaction of $1 \mathrm{a}(2.565 \mathrm{~g} ; 30.1 \mathrm{mmol})$ with water $(5.00 \mathrm{~g} ; 277 \mathrm{mmol})$ was carried out at $60^{\circ} \mathrm{C}$ for $24 \mathrm{~h}$, and the reaction mixture was separated by reduced distillation. Yield of adduct 4 was $1.908 \mathrm{~g}(62 \%)$. bp $115-117^{\circ} \mathrm{C} / 1 \mathrm{mmHg} \quad\left(\mathrm{Lit}^{10} ; 120^{\circ} \mathrm{C} / 0.03 \mathrm{mmHg}\right)$. IR (neat); $3300(\mathrm{OH}), 2934(\mathrm{CH}), 1637(\mathrm{C}=\mathrm{O})$, and $1558 \mathrm{~cm}^{-1}(\mathrm{NH}) .{ }^{1} \mathrm{H}$ NMR $\left(\mathrm{CDCl}_{3}, \mathrm{TMS}\right) ; \delta 1.94(\mathrm{~s}$, $\left.3 \mathrm{H}, \mathrm{CO}-\mathrm{CH}_{3}\right), 3.35\left(\mathrm{t}, \mathrm{J}=6.2 \mathrm{~Hz}, 2 \mathrm{H}, \mathrm{O}-\mathrm{CH}_{2}\right), 3.65(\mathrm{dt}$, $\left.J_{\mathrm{ab}}=J_{\mathrm{ac}}=6.2 \mathrm{~Hz}, 2 \mathrm{H}, \mathrm{N}-\mathrm{CH}_{2}\right), 4.75(\mathrm{br} \mathrm{s}, 1 \mathrm{H}, \mathrm{OH})$, and $7.30 \mathrm{ppm}$ (brs, 1H, NH).

\section{Typical Procedure for Addition Reaction of Poly(2- isopropenyl-2-oxazoline) (5) with Thiol}

To polymer $5(0.444 \mathrm{~g} ; 4 \mathrm{mmol})$ in a mixed solvent of NMP $(2.8 \mathrm{ml})$ and water $(1.2 \mathrm{ml})$ was added $2 \mathrm{a}(0.440 \mathrm{~g}$; $4 \mathrm{mmol}$ ). The mixture was stirred at $60^{\circ} \mathrm{C}$ for $5 \mathrm{~h}$ under nitrogen, poured into diethyl ether, reprecipitated twice from THF into diethyl ether, and dried in vacuo at $50^{\circ} \mathrm{C}$. Yield of polymer 6a was $0.775 \mathrm{~g}(87 \%)$. Degree of addition of $\mathbf{2 a}$ was $100 \%$, as calculated from the intensity ratio of ${ }^{1} \mathrm{H}$ NMR spectrum between $\mathrm{CH}_{3}$ and $\mathrm{CH}_{2}$ protons of the main chain at $0.50-2.40 \mathrm{ppm}$ and newly appeared phenyl protons at $6.72-7.60 \mathrm{ppm}$. IR (KBr); $3364(\mathrm{NH}), 3050$ and $2942(\mathrm{CH}), 1646(\mathrm{C}=\mathrm{O})$, and 1553 $(\mathrm{NH}) \mathrm{cm}^{-1} .{ }^{1} \mathrm{H} \mathrm{NMR}\left(\mathrm{CDCl}_{3}, \mathrm{TMS}\right) ; \delta 0.50-1.30(\mathrm{br}$, $\left.3 \mathrm{H}, \mathrm{CH}_{3}\right), 1.30-2.40$ (br, $2 \mathrm{H}, \mathrm{CH}_{2}$ in the main chain), $2.48-3.15$ and $3.15-3.96\left(\mathrm{br}, 4 \mathrm{H}, \mathrm{O}-\mathrm{CH}_{2}-\mathrm{CH}_{2}-\mathrm{N}\right)$, $5.72-6.60(\mathrm{br}, 1 \mathrm{H}, \mathrm{NH})$, and $6.72-7.60 \mathrm{ppm}(\mathrm{m}, 5 \mathrm{H}$, aromatic protons).

\section{Addition Reaction of Poly(2-isopropenyl-2-oxazoline) (5) with Benzoic Acid (2f)}

Polymer 5 ( $0.444 \mathrm{~g} ; 4 \mathrm{mmol})$ was dissolved in a mixed solvent of NMP $(2.8 \mathrm{ml})$ and water $(1.2 \mathrm{ml})$, and benzoic acid $(\mathbf{2 f})(0.488 \mathrm{~g} ; 4 \mathrm{mmol})$ was added to the solution. The mixture was stirred at $60^{\circ} \mathrm{C}$ for $24 \mathrm{~h}$ under nitrogen, poured into diethyl ether, reprecipitated twice from THF into diethyl ether, and dried in vacuo at $50^{\circ} \mathrm{C}$. Yield of polymer $\mathbf{6 f}$ was $0.686 \mathrm{~g}(91 \%)$. The degree of addition of 6 f was $64 \%$, determined by the ${ }^{1} \mathrm{H}$ NMR spectrum as in the case of polymer 6a. IR $(\mathrm{KBr}) ; 3404(\mathrm{NH})$, 3050 and $2954(\mathrm{CH}), 1715$ and $1646(\mathrm{C}=\mathrm{O})$, and 1274 $(\mathrm{C}-\mathrm{O}-\mathrm{C}) \mathrm{cm}^{-1} \cdot{ }^{1} \mathrm{H}$ NMR $\left(\mathrm{CDCl}_{3}, \mathrm{TMS}\right) ; \delta 0.50-1.45$ (br, $\left.3 \mathrm{H}, \mathrm{CH}_{3}\right), 1.45-2.55\left(\mathrm{br}, 2 \mathrm{H}, \mathrm{CH}_{2}\right.$ in the main chain), 2.55-3.15 and $3.15-3.85$ (br, $2.6 \mathrm{H}, \mathrm{O}-\mathrm{CH}_{2}$ $\left.\mathrm{CH}_{2}-\mathrm{N}\right), 3.85-4.15$ and $4.15-4.65\left(\mathrm{br}, 1.4 \mathrm{H}, \mathrm{O}-\mathrm{CH}_{2}-\right.$ $\mathrm{CH}_{2}-\mathrm{N}$ in oxazoline ring), $5.72-6.60$ (br, $\left.0.6 \mathrm{H}, \mathrm{NH}\right)$, and $7.10-8.10 \mathrm{ppm}(\mathrm{m}, 3.3 \mathrm{H}$, aromatic protons).

\section{REFERENCES}

1. For example; a) C. M. Starks, J. Am. Chem. Soc., 93, 195 (1971) b) W. P. Wever and C. W. Gokel, "Phase Transfer Catalysis in Organic Synthesis," Springer-Verlag, Heidelberg, 1997. c) C. M. Starks and C. Liotta, "Phase Transfer Catalysis," Academic Press, New York, N.Y., 1978

2. For example; a) Y. Imai, J. Macromol. Sci.-Chem., A15, 833 (1981). b) A. K. Banthia, D. Lunsford, D. C. Webster, and J. E McGrath, J. Macromol. Sci.-Chem., A15, 943 (1981). c) Y. Imai, J. Syn. Org. Chem. Jpn., 42, 1095 (1984). 
3. For example; a) J. M. J. Frechet, J. Macromol. Sci.-Chem., A15, 877 (1981). b) T. Nishikubo, Kobunshi (High Polymers, Jpn.), 35, 132 (1986). c) T. Nishikubo and T. Iizawa, J. Synth. Org. Chem. Jpn., 51, 157 (1993).

4. a) D. C. Rideout and R. Breslow, J. Am. Chem. Soc., 102, 7816 (1980). b) R. Breslow, U. Maitra, and D. Rideout, Tetrahedron Lett., 24, 1901 (1983).

5. a) P. A. Grieco, K. Yoshida, and P. Garner, J. Org. Chem., 48, 3137 (1983). b) P. A. Grieco, P. Garner, and Z. He, Tetrahedron Lett., 24, 1897 (1983).

6. a) S. Kobayashi, Chem. Lett., 2187 (1991). b) S. Kobayashi and I. Hachiya, Tetrahedron Lett., 33, 1625 (1992). c) S. Kobayashi and I. Hachiya, J. Org. Chem., 59, 3590 (1994).

7. a) T. Nishikubo, T. Iizawa, and A. Tokairin, Makromol. Chem., Rapid Commun., 2, 91 (1981). b) T. Nishikubo, T. Iizawa, and A. Tokairin, Makromol. Chem., 185, 1307 (1984).

8. a) T. Nishikubo, A. Tokairin, M. Takahashi, W. Nosaka, and T.
Iizawa, J. Polym. Sci., Polym. Chem. Ed., 23, 1805 (1985). b) T. Nishikubo, T. Iizawa, M. Takahashi, and A. Tokairin, J. Polym. Sci., Polym. Chem. Ed., 25, 2931 (1987).

9. S. Saito, H. Tamai, Y. Usui, M. Inaba, and T. Moriwake, Chem. Lett., 1243 (1984).

10. G. R. Porter, H. N. Rydon, and J. A. Schofield, J. Chem. Soc. II, 2686 (1960).

11. a) R. B. Martin and A. Parcell, J. Am. Chem. Soc., 83, 4835 (1961). b) R. B. Martin, R. I. Hedrick, and A. Parcell, J. Org. Chem., 29, 3197 (1964).

12. W. Seeliger, E. Aufderhaar, W. Diepers, R. Feinauer, R. Nehring, W. Thier, and H. Hellmann, Angew. Chem. Int. Ed. Engl., 5, 875 (1966).

13. R. R. Schmidt, Synthesis, 333 (1972).

14. A. Bewick, D. E. Goe, J. M. Mellor, and W. M. Owton, J. Chem. Soc., Perkin Trans. 1, 1033 (1985). 